Gut, 1971, 12, 528-540

\title{
Ileostomy and excisional surgery for chronic inflammatory disease of the colon: A survey of one hospital region
}

\author{
JEAN K. RITCHIE \\ From the Research Department, St. Mark's Hospital, London
}

SUMMARY Four hundred and fifty-three patients who underwent ileostomy and excisional large bowel surgery for chronic inflammatory disease at two teaching hospitals and 35 non-teaching hospitals within the North East Metropolitan Hospital Region during the years 1955-66 were surveyed through a study of hospital case records. The surgical results and complications are presented in part I ; a study of the health of these patients after their discharge from hospital is made in part II in an attempt to answer the question posed by many ileostomists, "Are we as healthy as other people?'

\section{Part I Results and complications of surgery}

Published reports on the results of colectomy and ileostomy for inflammatory bowel disease have previously been confined to patients operated upon by a single surgeon or a small group of surgeons at a single hospital. These reports, while giving information on surgical results in expert hands, may well not be representative of the situation in the country as a whole: this paper is an analysis of a sample of patients treated at a number of hospitals.

\section{Source of Data and Method of Study}

A survey has been made of all patients operated upon in the hospitals of the North East Metropolitan Hospital Region during the years 1955 to 1966; patients were followed up until 31 December 1967. Thus surgical results could be assessed over an extended period and patients followed for at least one year after surgery. The figures of this survey relate almost entirely to previously unpublished material. A very small number of these patients, however (including one patient who underwent surgery while pregnant), are among those already published (Boxall, 1966) while two cases of carcinoma included here were reported some years ago (Todd, 1961 : Aylett, 1966).

Patients from all general hospitals were included with the exception of one which only became part of the region in 1965. As a special centre, St. Mark's Hospital was excluded. The two criteria for inclusion

Received for publication 3 May 1971. of a patient were (a) an age of 14 years or over at the time of the establishment of the permanent ileostomy, 'permanent' in this context being defined as present up to the time of death or until the end of the followup period, and $(b)$ that the actual operation of ileostomy should have been undertaken in these hospitals.

The main methods used to discover the relevant case notes were (1) the membership register of the Ileostomy Association; (2) the disease index or, more frequently, the operation index; (3) the records of the pathological laboratory; (4) interrogation of surgeons and other staff, and (5) the operation registers. The resultant sample can be regarded as almost complete and is considered sufficient for the purpose of this enquiry. The case records of all patients were studied at the hospital where the surgery had been carried out. Where necessary for follow-up purposes further information was obtained from other hospitals or, more frequently, from general practitioners. No patients were interviewed and no questionnaires were sent out.

Ileostomies for chronic inflammatory disease of the colon had been carried out at 37 hospitals: 453 patients had been treated in this way, 126 at the two teaching hospitals and 327 at the non-teaching hospitals.

\section{Pathology}

The attempt to divide the cases into examples of ulcerative colitis, Crohn's disease, or 'unclassified' 
colitis was not completely successful but 35 cases of Crohn's disease were separated from the total number by $(a)$ the acceptance of this diagnosis if given in the original pathological report and $(b)$ requests for histological review in any doubtful cases. It seems probáble that this number of 35 is an underestimate and that a total review in the light of more recent knowledge of the pathology of Crohn's disease might well have resulted in a very different histological assessment.

No pathological report was obtainable for eight patients considered clinically as cases of ulcerative colitis; in four patients only a rectal biopsy report was available and in a further eight only the report on the excised rectum.

In the analyses that follow, the cases of Crohn's disease have been included. Where relevant, particular features in the management of these patients are specifically mentioned.

\begin{tabular}{|c|c|c|c|c|c|c|}
\hline \multirow{2}{*}{$\begin{array}{l}\text { Age } \\
\text { Group } \\
(y r)\end{array}$} & \multicolumn{2}{|c|}{ Male } & \multicolumn{2}{|c|}{ Female } & \multicolumn{2}{|c|}{$A l l$} \\
\hline & No. & & No. & & No. & \\
\hline $\begin{array}{l}14-19 \\
20-24 \\
25-29 \\
30-34 \\
35-39 \\
40-44 \\
45-49 \\
50-54 \\
55-59 \\
60-64 \\
65-69 \\
70-74 \\
75-79 \\
80-84\end{array}$ & $\begin{array}{l}12 \\
17 \\
16 \\
18 \\
25 \\
15 \\
16 \\
31 \\
12 \\
10 \\
8 \\
5 \\
2 \\
-\end{array}$ & $\begin{array}{r}(6.4 \%) \\
(9.1 \%) \\
(8.6 \%) \\
(9.6 \%) \\
(13.4 \%) \\
(8.0 \%) \\
(8.6 \%) \\
(16.5 \%) \\
(6.4 \%) \\
(5.3 \%) \\
(4.3 \%) \\
(2.7 \%) \\
(1.1 \%) \\
-\end{array}$ & $\begin{array}{l}11 \\
16 \\
21 \\
33 \\
35 \\
24 \\
33 \\
23 \\
20 \\
22 \\
13 \\
12 \\
1 \\
2\end{array}$ & $\begin{array}{r}(4.1 \%) \\
(6.0 \%) \\
(7.9 \%) \\
(12.4 \%) \\
(13.2 \%) \\
(9.0 \%) \\
(12.4 \%) \\
(8.6 \%) \\
(7.5 \%) \\
(8.3 \%) \\
(4.9 \%) \\
(4.5 \%) \\
(0.4 \%) \\
(0.8 \%)\end{array}$ & $\begin{array}{r}23 \\
33 \\
37 \\
51 \\
60 \\
39 \\
49 \\
54 \\
32 \\
32 \\
21 \\
17 \\
3 \\
2\end{array}$ & $\begin{array}{r}(5.1 \%) \\
(7.3 \%) \\
(8.2 \%) \\
(11.2 \%) \\
(13.3 \%) \\
(8.6 \%) \\
(10.8 \%) \\
(11.9 \%) \\
(7.1 \%) \\
(7.1 \%) \\
(4.6 \%) \\
(3.7 \%) \\
(0.7 \%) \\
(0.4 \%)\end{array}$ \\
\hline Total & 187 & $100.0 \%$ & 266 & $(100.0 \%)$ & 453 & $(100.0 \%)$ \\
\hline
\end{tabular}

Table 1 Age and sex distribution in 453 cases

\section{Description of the Series}

The age and sex distribution is shown in Table I. Age, defined as age last birthday, is that at the time of the establishment of the permanent ileostomy. The mean age at ileostomy for men was 42.5 years, for women $44 \cdot 2$ years, and for all cases $43 \cdot 6$ years.
The length of history, known in 443 cases, is defined as the duration of symptoms to the construction of the permanent ileostomy and is shown in Table II.

\begin{tabular}{lc}
\hline Length of History $(y r)$ & No. of Cases \\
\hline$<1$ & 119 \\
$(<1$ month $6,>1<6$ months $77,>6<12$ months 36$)$ \\
$>1<5$ & 141 \\
$>5<10$ & 84 \\
$>10<20$ & 69 \\
$>20$ & 30 \\
\hline
\end{tabular}

Table II Length of history in 443 cases

The history was of the continuous type in 161 cases (including eight with Crohn's disease), ie, $36.3 \%$ of those for whom there was an accurate record. One hundred of these 161 patients had a history of less than one year.

Preoperative complications, recordable in 450 patients, were found in 197 cases $(43 \%)$ and are shown in Table III where the figures in brackets show the number of patients with Crohn's disease.

PREOPERATIVE SEVERITY OF THE DISEASE

Patients were graded (Table IV) according to their preoperative clinical condition using the criteria of Ewart and Lennard-Jones (1960).

Group A: Good general condition, inactive colitis. Group B: Good general condition, mild active colitis. Group C: Poor general condition and/or severe active colitis.

Group D: Emergency operation for critically ill patients.

'Preoperative condition' in this study relates to the period immediately before the establishment of the ileostomy and thus grading was impossible in patients where this was not the first definitive surgery.

TREATMENT WITH CORTICOSTEROIDS

An attempt to make some comparison between patients who had received preoperative treatment with corticosteroids and those in whom no such drugs had been given had to be abandoned.

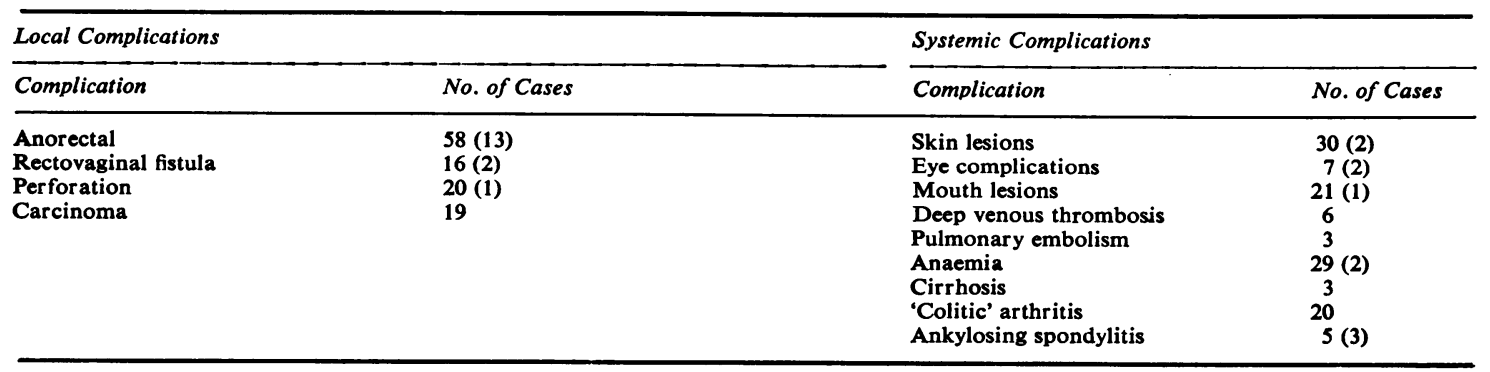




\begin{tabular}{|c|c|c|c|c|c|c|}
\hline \multirow[t]{2}{*}{ Source } & \multicolumn{4}{|l|}{ Grading } & \multirow{2}{*}{$\begin{array}{l}\text { Impossible or } \\
\text { Unknown }\end{array}$} & \multirow[t]{2}{*}{ Total } \\
\hline & $A$ & $\boldsymbol{B}$ & $\boldsymbol{C}$ & $\boldsymbol{D}$ & & \\
\hline $\begin{array}{l}\text { Non-teaching hospitals } \\
\text { Teaching hospitals }\end{array}$ & $\begin{array}{l}4(1 \cdot 2 \%) \\
2(1.6 \%)\end{array}$ & $\begin{array}{r}123(37 \cdot 6 \%) \\
52(41 \cdot 3 \%)\end{array}$ & $\begin{array}{l}97(29.7 \%) \\
26(20.6 \%)\end{array}$ & $\begin{array}{l}46(14 \cdot 1 \%) \\
26(20.6 \%)\end{array}$ & $\begin{array}{l}57(17.4 \%) \\
20(15.9 \%)\end{array}$ & $\begin{array}{l}327(100 \cdot 0 \%) \\
126(100 \cdot 0 \%)\end{array}$ \\
\hline Total & $6(1 \cdot 3 \%)$ & $175(38.6 \%)$ & $123(27 \cdot 2 \%)$ & $72(15.9 \%)$ & $77(17.0 \%)$ & $453(100 \cdot 0 \%)$ \\
\hline
\end{tabular}

Table IV Preoperative grading in 453 cases

Only $28.3 \%$ of patients undergoing colectomy and ileostomy and $24.7 \%$ of those treated by total proctocolectomy had not received either systemic or local rectal steroids in the year preceding surgery.

YEAR OF SURGERY

Table V shows the spread of the cases over the period of the survey. The number of cases increased in the later years, 186 having had surgery in the years $1955-60$ and 267 in the years 1961-66. This rise was mainly due to the increasing number of cases operated upon in the non-teaching hospitals with a peak incidence in all hospitals in the year 1964.

TYPES OF OPERATION

As this survey covered the work of some 60 surgeons over a 12-year period, there was, naturally, considerable variation in the surgical approach. The main operations carried out are shown in Table VI.

Table VI shows that ileostomy and total or subtotal colectomy was the commonest operation in all hospitals. Total proctocolectomy showed an increasing incidence over the years of the survey rising from $14.5 \%$ (of 186 operations) in the years $1955-60$ to $27.5 \%$ (of 267 operations) in the years 1961-66.

\section{Postoperative Mortality of the Primary Surgery}

Eighty-one patients died in the postoperative period, defined here as the 60 days following surgery: this gives an overall mortality rate for the surgery directed to the treatment of the disease of $17.9 \%$. This rate was $19.9 \%$ of 327 cases in the non-teaching hospitals and $12 \cdot 7 \%$ of 126 cases in the teaching hospitals.

Seventy-three patients died following the operation at which the ileostomy was established: 13 after total proctocolectomy (12.9\% of 101 cases), 35 after colectomy and ileostomy (15.5\% of 226 cases), 13 after ileostomy alone as the first surgery $(29.5 \%$ of 44 cases), and 12 after ileostomy with or without partial removal of the colon or rectum not undertaken as the first surgical treatment. Six deaths occurred after colectomy following an initial ileostomy and two after rectal excision.

Excision of the rectum was undertaken during the years 1955-67 in 203 patients excluding those treated by one-stage total proctocolectomy and ileostomy. Four deaths occurred postoperatively and are included in those detailed above. There were 70 patients alive at the end of the follow-up period in whom the rectum had not been excised.

\section{FACTORS INFLUENCING POSTOPERATIVE MORTALITY}

\section{Age}

Of the 292 patients aged between 14 and 49 years, 32 $(11 \%)$ died after the operation at which the ileostomy was established: 161 patients were aged 50 years or

\begin{tabular}{|c|c|c|c|c|c|c|c|c|c|c|c|c|c|}
\hline \multirow[t]{2}{*}{ Source } & \multicolumn{12}{|l|}{ Year } & \multirow[t]{2}{*}{ Total No. } \\
\hline & 1955 & 1956 & 1957 & 1958 & 1959 & 1960 & 1961 & 1962 & 1963 & 1964 & 1965 & 1966 & \\
\hline Total & 30 & 34 & 28 & 35 & 33 & 26 & 29 & 48 & 36 & 60 & 48 & 46 & 453 \\
\hline
\end{tabular}

Table V Year of establishment of permanent ileostomy in 453 cases

\begin{tabular}{|c|c|c|c|c|c|c|}
\hline Source & $\begin{array}{l}\text { Colectomy and } \\
\text { Ileostomy }\end{array}$ & $\begin{array}{l}\text { Total } \\
\text { Proctocolectomy }\end{array}$ & $\begin{array}{l}\text { Ileostomy Alone as } \\
\text { First Operation }\end{array}$ & $\begin{array}{l}\text { Ileostomy } \pm \\
\text { Excision of Rectum } \\
\text { after Ileorectal } \\
\text { Anastomosis }\end{array}$ & Other Operations & Total \\
\hline $\begin{array}{l}\text { Non-teaching hospitals } \\
\text { Teaching hospitals }\end{array}$ & $\begin{array}{r}141 \\
85\end{array}$ & $\begin{array}{l}90 \\
11\end{array}$ & $\begin{array}{r}36 \\
8\end{array}$ & $\begin{array}{l}27 \\
12\end{array}$ & $\begin{array}{l}33 \\
10\end{array}$ & $\begin{array}{l}327 \\
126\end{array}$ \\
\hline Total & 226 & 101 & 44 & 39 & 43 & 453 \\
\hline
\end{tabular}

Table VI Surgery involving the establishment of an ileostomy in 453 cases 
over and $41(25.5 \%)$ died in this postoperative period. Table VII gives these figures in detail and shows clearly that postoperative mortality increased markedly with advancing age; a similar trend was found for the two standard operations of colectomy and ileostomy and total proctocolectomy.

\begin{tabular}{lccc}
\hline $\begin{array}{l}\text { Age Group } \\
(y r)\end{array}$ & $\begin{array}{l}\text { No. of } \\
\text { Operations }\end{array}$ & $\begin{array}{l}\text { No. of Post- } \\
\text { operative Deaths }\end{array}$ & $\begin{array}{l}\text { Percentage Postoperative } \\
\text { Mortality }\end{array}$ \\
\hline $14-19$ & 23 & 2 & $8 \cdot 7$ \\
$20-29$ & 70 & 7 & $10 \cdot 0$ \\
$30-39$ & 111 & 14 & $12 \cdot 6$ \\
$40-49$ & 88 & 9 & $10 \cdot 2$ \\
$50-59$ & 86 & 18 & $20 \cdot 9$ \\
$60-69$ & 53 & 15 & $28 \cdot 3$ \\
$70-79$ & 20 & 7 & $35 \cdot 0$ \\
$80-89$ & 2 & 1 & $50 \cdot 0$ \\
Total & 453 & 73 & Overall \\
\hline
\end{tabular}

Table VII Postoperative mortality related to age of patient at all hospitals for all operations involving an ileostomy in 453 cases

Preoperative severity of the disease

As preoperative grading was impossible in 77 cases, analysis of this factor in postoperative mortality has been limited to patients undergoing colectomy and ileostomy or total proctocolectomy and is given in Table VIII.

\begin{tabular}{|c|c|c|c|}
\hline Grade & $\begin{array}{l}\text { No. of } \\
\text { Operations }\end{array}$ & $\begin{array}{l}\text { No. of Post- } \\
\text { operative Deaths }\end{array}$ & \\
\hline \multicolumn{4}{|c|}{ Colectomy and Ileostomy at Non-teaching Hospitals (141 cases } \\
\hline B & 56 & 1 & $(1.8 \%)$ \\
\hline C & 55 & 11 & $(20.0 \%)$ \\
\hline D & 28 & 14 & $(50.0 \%)$ \\
\hline Unknown & 2 & 0 & \\
\hline Total & 141 & Overall & $(18.4 \%)$ \\
\hline \multicolumn{4}{|c|}{ Colectomy and Ileostomy at Teaching Hospitals (85 cases) } \\
\hline A \& B & 39 & 0 & \\
\hline C & 22 & 1 & (4.5\%) \\
\hline D & 24 & 8 & $(33 \cdot 3 \%)$ \\
\hline Total & 85 & Overall & $(10 \cdot 6 \%)$ \\
\hline \multicolumn{4}{|c|}{ Total Proctocolectomy Performed at All Hospitals (101 cases) } \\
\hline & 2 & 0 & \\
\hline B & 69 & 7 & $(10 \cdot 1 \%)$ \\
\hline $\mathbf{C}$ & 24 & 3 & $(12.5 \%)$ \\
\hline D & 5 & 3 & $(60.0 \%)$ \\
\hline Unknown & 1 & $\mathbf{0}$ & 0 \\
\hline Total & 101 & Overall & $(12.9 \%)$ \\
\hline
\end{tabular}

Table VIII Postoperative mortality and preoperative grading

The operation of colectomy and ileostomy carried a very low mortality $(1.05 \%)$ in all hospitals when undertaken electively in patients graded as A or B cases preoperatively. Increasing severity of the disease led to a rising postoperative mortality, considerably more evident in the non-teaching hospitals surveyed. A similar trend was seen for the smaller number of patients undergoing total proctocolectomy.

\section{Year of operation}

For all operations involving an ileostomy, the postoperative mortality was $17.2 \%$ in the first six-year period $1955-60$ and $15.4 \%$ in the years $1961-66$. The operation of colectomy and ileostomy showed a similar mortality of $15.0 \%$ and $15.8 \%$ in the two sixyear periods while mortality for total proctocolectomy fell from $18.5 \%$ (of 27 cases) in the years $1955-60$ to $10 \cdot 8 \%$ (of 74 cases) in the period 1961-66.

\section{Emergency surgery}

Seventy-two patients came to emergency surgery, an emergency operation being defined as one undertaken outside a normal operating list and/or within 12 hours of the decision to operate being taken. There were 46 such cases in the non-teaching hospitals with an overall mortality rate of $52.2 \%$. In the teaching hospitals the mortality rate was $30.8 \%$ in 26 cases.

Forty-four patients were less than 50 years of age and 16 died postoperatively $(36.4 \%)$ : 28 patients were aged 50 years or over and 16 died $(57 \cdot 1 \%)$. All six patients of 70 years or over undergoing emergency surgery died in the ensuing 60 days.

Emergency operations were carried out in 23 patients in the years 1955-60 with 10 deaths $(43.5 \%)$ and in 49 patients in the years 1961-66 with 22 deaths $(44.9 \%)$.

Total proctocolectomy was undertaken in five patients with three deaths, colectomy and ileostomy in 52 patients with 22 deaths, and ileostomy alone initially in 15 cases with five deaths after this operation and two following a subsequent colectomy.

In 20 patients (one of whom had Crohn's disease) the colon had perforated preoperatively and there were 13 postoperative deaths $(65 \%)$. The perforations were 'free' in 11 cases, with abscess formation in four, and sealed in five. In the remaining 52 patients coming to emergency surgery, there were 19 deaths $(36.5 \%)$. The site of perforation, recorded in 11 patients with 15 perforations, was the sigmoid colon in five, descending colon in two, splenic flexure in one, transverse colon in three, and the caecum or ascending colon in six. Perforation occurred in 19 patients with ulcerative colitis; seven were in the first attack of their disease, 11 were definitely not in their first attack, and in one this point was uncertain.

The main factors leading to emergency surgery were (a) acute fulminating disease failing to respond to medical treatment in 21 patients; $(b)$ a preoperative diagnosis of perforation in 21 cases; (c) acute deterioration in the general condition in 19 
cases; $(d)$ severe dilatation of the colon in seven patients; and $(e)$ haemorrhage in four cases.

Three patients underwent emergency surgery while pregnant. Two patients survived; in one, the pregnancy proceeded to term. The third patient aborted following surgery and died subsequently.

\section{PATHOLOGY AND CAUSES OF POSTOPERATIVE} DEATHS

Of the 81 postoperative deaths, seven were in patients with carcinoma; in two, the ileostomy was a purely palliative procedure. Five patients with Crohn's disease died postoperatively. In the remaining 69 cases, the diagnosis of ulcerative colitis was supported in one case by a rectal biopsy report and in 61 cases by a histological report on the colon.

The causes of death as recorded in the case notes (verified by necropsy in 42 cases) or on the death certificate (nine cases) are given in Table IX.

\begin{tabular}{lc}
\hline Cause & No. of Patients \\
\hline Peritonitis & 19 \\
Paralytic ileus & 5 \\
Intestinal obstruction & 2 \\
Liver failure & 3 \\
Renal failure & 3 \\
Systemic infection & 5 \\
Cardiovascular conditions & 12 \\
Bronchopneumonia & 13 \\
Postoperative shock & 4 \\
Toxaemia & 3 \\
Crohn's disease & 1 \\
Ulcerative colitis & 11 \\
\hline
\end{tabular}

Table IX Causes of postoperative deaths in 81 cases

LATE DEATHS WHILE STILL IN HOSPITAL

Four patients died at intervals of more than 60 days from the primary surgery while still in hospital. The respective causes were cerebral thrombosis, bronchopneumonia following ileostomy resiting, Crohn's disease, and carcinomatosis.

\section{Postoperative Complications}

This section is limited to patients undergoing standard surgery. For both proctocolectomy and colectomy and ileostomy in both non-teaching and teaching hospitals, the postoperative period was free of complications in rather less than half of the patients. The incidence of complications rose steadily with increasing severity of the disease. Fifty-three per cent of patients having elective surgery (A and B) had no complications postoperatively: this percentage fell to $44 \%$ for those having urgent surgery (C) and $19.3 \%$ for those undergoing emergency surgery (D). With the postoperative deaths excluded, the incidence of major, ie, potentially life-threatening complications, was $14.5 \%$ for the A and B cases, $20.0 \%$ for the $C$ cases, and $37.5 \%$ for the $D$ cases.

Using the duration of postoperative inpatient stay as a measure of complications, it was found that for patients treated by colectomy and ileostomy, $44.7 \%$ of the A and B cases were discharged from hospital in 28 days or less, $27.0 \%$ of the $C$ cases, and $14.0 \%$ of the $\mathrm{D}$ cases. For patients treated by total proctocolectomy the respective figures were $35.0 \%, 23.8 \%$, and $0 \%$.

Seven patients required reconstruction of the ileostomy in the postoperative period and are included among the cases described later.

\section{THE PERINEAL WOUND}

Two hundred and eighty-three patients left hospital with a perineal wound and survived for at least one year. The time taken for healing of the wound is shown in Table X.

Thirty-three patients with ulcerative colitis (with a total of 46 admissions) required readmission for surgery to the perineal wound, a patient readmission rate of $12.5 \%$ and the average time spent in hospital was $\mathbf{2 3 . 3}$ days. Six patients with Crohn's disease (with a total of 13 admissions) required this further surgery, a patient readmission rate of $30 \%$.

\section{INTESTINAL OBSTRUCTION}

\section{Complete small intestinal obstruction}

Obstruction was complete in 39 patients and in three cases incomplete obstruction was treated surgically. These figures relate only to obstruction occurring after the establishment of the ileostomy. The patient reoperation rate for the complication was $9.3 \%$ (42 patients out of 453). Table XI relates the incidence of obstruction to the type of previous surgery and shows the postoperative incidence and the late incidence.

Two patients each required two laparotomies

\begin{tabular}{|c|c|c|c|c|c|c|c|}
\hline \multirow[t]{3}{*}{ Diagnosis } & \multirow[t]{3}{*}{ No. of Cases } & \multicolumn{6}{|c|}{ Number of Months } \\
\hline & & \multirow[t]{2}{*}{$<6$} & \multirow[t]{2}{*}{$>6<12$} & \multirow[t]{2}{*}{$>12$} & \multirow[t]{2}{*}{ Unknown } & \multicolumn{2}{|l|}{ Readmissions } \\
\hline & & & & & & No. of Cases & No. of Readmissions \\
\hline $\begin{array}{l}\text { Ulcer ative colitis } \\
\text { Crohn's disease }\end{array}$ & $\begin{array}{r}263 \\
20\end{array}$ & $\begin{array}{r}121 \\
4\end{array}$ & $\begin{array}{r}41 \\
7\end{array}$ & $\begin{array}{r}60 \\
8\end{array}$ & $\begin{array}{r}41 \\
1\end{array}$ & $\begin{array}{r}33 \\
6\end{array}$ & $\begin{array}{l}46 \\
13\end{array}$ \\
\hline
\end{tabular}

Table X Time (in months) taken for healing of perineal wound in 283 cases 


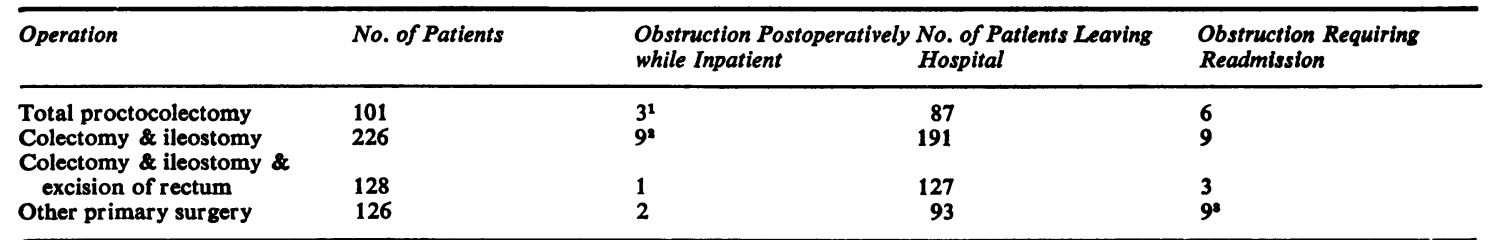

Table XI Incidence of small intestinal obstruction requiring operation related to type of previous surgery in 42 cases

'One patient died 'Three patients died 'One patient died

giving a total of 44 operations carried out for obstruction. The causes were adhesions on 27 occasions, a volvulus in five patients, a loop of gut becoming kinked around the rectal stump in two cases, and miscellaneous causes in four instances. Lateral space obstruction occurred in six cases although in three patients this was definitely stated to have been closed at operation.

The surgical treatment of patients readmitted with obstruction had a low mortality rate: one death occurred after 29 operations (3.4\%). The time spent in hospital for this surgery ranged from nine to 45 days with an average stay of $\mathbf{1 9 \cdot 5}$ days.

\section{Incomplete intestinal obstruction}

This was responsible for 22 patients (with a total of 26 admissions) being readmitted. In all cases treatment was conservative but four patients required laparotomy for complete obstruction subsequently and, in one, adhesions were divided when the rectum was excised. The average time spent in hospital for this complication was 5.8 days (range 1-22 days).

\section{RECONSTRUCTION AND RESITING OF THE ILEOSTOMY}

Forty-nine patients required resiting of the ileostomy or reconstruction on one or more occasions, giving a patient reoperation rate for these complications of $10.8 \%$. Four patients died following this surgery.

In all, a total of 67 operations were carried out on these 49 patients, 26 patients (with a total of 37 admissions) being readmitted especially for this further surgery. Resiting was required on 12 occasions. The reason for this was known in nine cases and was poor siting in four cases, skin excoriation in two, fistula in two, and prolapse in one. The reasons for surgery were known in $\mathbf{4 5}$ of the 55 reconstructions carried out and were retraction in 14 cases, prolapse in 11, stenosis in 10, fistula in eight, and impairment of the blood supply in the remaining two.

In the first six years of this survey, 1955-60, an ileostomy was established in 186 patients: 32 required reconstruction or resiting $(17 \cdot 2 \%)$. In the years 1961-66, only 17 patients out of a total of 267 required this further surgery $(6.4 \%)$. The time spent in hospital for these operations varied from three to 65 days with an average time of $18 \cdot 2$ days.

FURTHER COMPLICATIONS REQUIRING READMISSION TO HOSPITAL

\section{Gastrointestinal upsets}

Twenty-six patients (with a total of 31 admissions) were readmitted with various types of gastrointestinal upset not considered to be due to obstruction. In four patients, the condition was thought to be infective, in 11 the symptoms were associated with excessive ileostomy action, and the remaining 11 patients had acute or subacute upsets usually presenting with abdominal pain and nausea or vomiting. Conservative management led to resolution of the condition in all cases: the average duration of stay in hospital in these cases was 10.3 days (range 1-40 days).

\section{Local ileostomy conditions}

Thirty-nine patients (with a total of 49 admissions) required a further period in hospital for the treatment of local ileostomy complications and the reasons for these readmissions are given in Table XII.

The patients in this group spent an average of 12.6 days in hospital (range 1-48 days).

\begin{tabular}{ll}
\hline Cause & No. of Admissions \\
\hline Skin excoriation & 11 \\
Prolapse & 6 \\
For dilatation of ileostomy & 5 \\
Bleeding & 4 \\
Para-ileostomy abscess & 4 \\
Para-ileostomy sinus & 3 \\
Para-ileostomy hernia & 3 \\
Ileostomy education & 3 \\
Oedema & 2 \\
Fistula & 2 \\
Ulceration & 2 \\
Other & 4 \\
\hline
\end{tabular}

Table XII Local ileostomy conditions leading to hospital readmission in 49 admissions

Abdominal wound conditions

Fourteen patients were readmitted for treatment to 
the abdominal wound. In two patients a length of wire was removed, in 12 there was infection usually with abscess formation, and four patients underwent repair of an incisional hernia. Two further patients had a hernia of this type repaired at the time of subsequent surgery; six patients only therefore in this series required incisional herniorrhaphy. The average duration of stay in hospital for these 14 patients was $14 \cdot 4$ days (range $5-40$ days).

\section{Other related complications}

Fifteen patients (with a total of 18 admissions) required inpatient treatment for conditions referable to the previous surgery but not included in any of the above categories. These included abdominal wall abscesses or sinuses, fistulae, and intra- or retroperitoneal abscesses. The average time spent in hospital for these conditions was 24 days (range 3-46 days).

\section{Total number of readmissions}

Table XIII shows the number of patients readmitted for complications up to the end of the follow-up period. Patients who were admitted for sigmoidoscopy or for treatment to the rectum have not been included in these figures. Also excluded are six patients with Crohn's disease with abdominal symptoms and all readmissions necessitated by recurrent malignant disease.
The number of patients at risk for the complications shown in the first section of Table XIII was 371 ( 82 of the 453 patients in the series did not leave hospital alive after the ileostomy) and when allowance is made for multiple admissions of the same patient, it is found that 128 patients $(34.5 \%)$ required further hospital treatment. Thirty-nine patients $(13.8 \%)$ of the 283 who left hospital with a perineal wound required further surgery for the wound. Of these 39 patients, 25 had not been readmitted for other complications and the total number of patients readmitted for complications referable to the previous surgery was therefore 153 .

The date of readmission for the first seven complications shown in Table XIII relative to the date of surgery was recorded for all cases and these figures are shown in Table XIV.

\section{Carcinoma of the Colon or Rectum}

In 19 patients in this study carcinoma arose in a colon or rectum already affected by ulcerative colitis. Radical surgical treatment was undertaken in 12 patients and palliative operations in seven. Seven patients died in the postoperative period: in three the surgery had been radical. Eight patients died at intervals of three to 32 months following surgery, death being due to recurrent tumour or metastases in all but one instance. Four patients were

\begin{tabular}{|c|c|c|c|c|}
\hline Cause & $\begin{array}{l}\text { Number of Patients } \\
\text { Readmitted }\end{array}$ & $\begin{array}{l}\text { Number of } \\
\text { Readmissions }\end{array}$ & $\begin{array}{l}\text { Patient Readmission } \\
\text { Rate }(\%)\end{array}$ & $\begin{array}{l}\text { Total Readmission } \\
\text { Rate }(\%)\end{array}$ \\
\hline $\begin{array}{l}\text { Number of Patients at Risk } 371 \\
\text { Complete intestinal obstruction } \\
\text { Incomplete intestinal obstruction } \\
\text { Reconstruction or resiting } \\
\text { Gastrointestinal upsets } \\
\text { Local ileostomy conditions } \\
\text { Abdominal wound } \\
\text { Other related complications }\end{array}$ & $\begin{array}{l}27 \\
22 \\
26 \\
26 \\
39 \\
14 \\
15\end{array}$ & $\begin{array}{l}29 \\
26 \\
37 \\
31 \\
49 \\
14 \\
18\end{array}$ & $\begin{array}{r}7.3 \\
5.9 \\
7.0 \\
7.0 \\
10.5 \\
3.8 \\
4.0\end{array}$ & $\begin{array}{r}7.8 \\
7.0 \\
10.0 \\
8.4 \\
13.2 \\
3.8 \\
4.8\end{array}$ \\
\hline $\begin{array}{l}\text { Number of Patients at Risk } 283 \\
\text { Perineal wound }\end{array}$ & 39 & 59 & $13 \cdot 8$ & $20 \cdot 8$ \\
\hline
\end{tabular}

Table XIII Readmissions for various complications

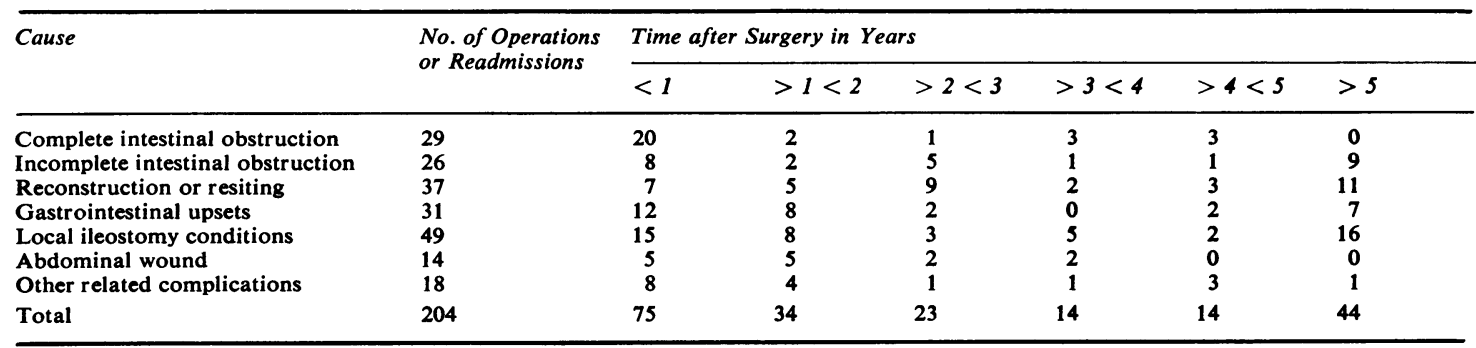

Table XIV Interval between surgery and complications 
alive at the end of the follow-up period with survival times ranging from two to nine years.

\section{Discussion}

This paper is an analysis of surgery involving the establishment of an ileostomy in $\mathbf{4 5 3}$ patients with chronic inflammatory disease of the colon operated upon in 37 hospitals of one hospital region during the years 1955-66. Three hundred and twenty-seven patients $(72.2 \%)$ underwent standard surgery, ie, colectomy and ileostomy or total proctocolectomy in the first instance; the former operation was the commonest surgical approach in all hospitals over the 12-year period and showed an incidence of between $40 \%$ and $60 \%$ in each year. Total proctocolectomy became more frequent in the latter years, its incidence almost doubling in the second six years compared with the first. The overall mortality of the primary surgery was $17.9 \%$. No directly comparable group, ie, composed of patients from a large number of hospitals, exists in the literature: figures for patients with ulcerative colitis from special centres in this country show an overall mortality rate of $10.4 \%$ in 442 cases operated upon in the years 1947-66 in Birmingham (Daly and Brooke, 1967), $12 \%$ in 151 patients undergoing surgery in the years 1955-63 in Leeds (Watts, de Dombal, and Goligher, $1966 \mathrm{a})$, and $8 \%$ in 188 cases operated upon in the years 1955-66 at St. Mark's Hospital. It was to be expected that the operative mortality would be higher in the present group as such cases were an occasional rather than a regular occurrence in a number of these hospitals. The operative mortality for patients treated electively (A and B cases) by standard surgery in this study is not dissimilar from the figures for elective surgery in the other series, ie, present series $4.5 \%$, Birmingham series $3.4 \%$, Leeds series $3.8 \%$, St. Mark's Hospital series $2 \cdot 1 \%$.

It is widely recognized that emergency surgery in ulcerative colitis carries a high mortality and figures for this in the literature vary from $15 \%$ (Hughes, 1964 ) and $17.4 \%$ (Boxall, 1966) to $24 \%$ (Daly and Brook, 1967), 26.7\% (Watts et al, 1966a), and $31 \%$ (Lennard-Jones and Vivian, 1960). The figure of $44.4 \%$ in the present series emphasizes the importance of avoiding such surgery whenever possible. In the severe case, intensive medical treatment can, in a number of instances, tide the patient over the acute phase and enable surgery where advisable to be undertaken later under more favourable conditions: when medical treatment fails to produce rapid improvement, then earlier resort to surgery can reduce the mortality as shown by Goligher, Hoffmann, and de Dombal (1970).

Perforation of the colon preoperatively occurred in 19 patients with ulcerative colitis in this study. Of this number, 11 patients were definitely not in the first attack of their disease; this finding is similar to that of Jalan, Sircus, Card, Falconer, Bruce, Crean, McManus, Small, and Smith (1969a) who found that, of 16 patients who sustained perforation, 11 did so during a relapse and only five in their first attack. Other authors (Edwards and Truelove, 1964; de Dombal, Watts, Watkinson, and Goligher, 1965) have found perforation to be more common during the initial attack of ulcerative colitis. Surgery in the presence of perforation carries a very poor prognosis: 13 of the 20 patients reported here died postoperatively. This incidence of $65 \%$ is almost identical with that of $66 \%$ (eight cases out of 12 patients) reported by Jalan et al (1969a).

SEQUELAE OF SURGERY

The date of healing of the perineal wound was known in 222 patients with ulcerative colitis. This occurred in less than six months in 121 cases $(54.5 \%)$. This figure is somewhat higher than that of $44 \%$ in 106 cases (Jalan, Smith, Ruckley, Falconer, Small, and Prescott, 1969b) but lower than the $75.3 \%$ in 93 patients recorded by Watts et al (1966b). It is well known that perineal wound healing may be even more delayed in patients with Crohn's disease and the findings here support this view: eight of the 19 patients $(42.1 \%)$ with this disease who underwent rectal excision had an unhealed perineal wound after one year compared with $27 \%$ (60 out of 222 ) of patients with ulcerative colitis while the readmission rate for treatment to the wound was $30 \%$ for patients with Crohn's disease and $12.5 \%$ for those with ulcerative colitis.

Intestinal obstruction requiring surgery occurred in 42 patients, an incidence of $9.3 \%$ very similar to that of $8.4 \%$ given by Watts et al (1966b) and $9 \%$ recorded by Daly and Brooke (1967). As has been found in other series, adhesions were responsible in the majority of cases $(64 \cdot 3 \%)$. It seems probable that obstruction as a complication of this surgery will continue to occur; it is, however, a well recognized sequela and surgery for patients readmitted with this condition carried a low mortality rate (3.4\%).

Forty-nine patients required reconstruction or resiting of the ileostomy, a reoperation rate of $10.8 \%$. This figure lies within the range of those reported from hospitals where large numbers of these cases are seen, eg, 3.7\% in 188 patients (St. Mark's Hospital figures), $6 \%$ in 100 patients (Daly and Brooke, 1967), and $11.8 \%$ in 119 patients (Watts et $a l, 1966 \mathrm{~b})$. Moreover the proportion of patients requiring this surgery fell markedly over the two six-year periods, ie, from $17.2 \%$ in the years $1955-60$ to $6.4 \%$ in the years $1961-66$. 
Other complications requiring readmission to hospital, ie, mainly gastrointestinal upsets and local ileostomy complications, are those to be found among any group of ileostomists. The number of patients readmitted with the latter conditions is probably higher in this study than at centres where special outpatient facilities exist for the treatment of ileostomy problems. It seems probable that the incidence of most of these later sequelae will continue to fall as did the reconstruction rate in this study as more surgeons and general practitioners become conversant with the problems involved.

References

Aylett, S. O. (1966). Three hundred cases of diffuse ulcerative colitis treated by total colectomy and ileor ectal anastomosis. Brit. med. $J ., 1,1001-1005$.

Boxall, T. A. (1966). Emergency surgery in ulcerative colitis. Gut, 7, 606-611.

Daly, D. W., and Brooke, B. N. (1967). Ileostomy and excision of the large intestine for ulcerative colitis. Lancet, 2, 62-64.

de Dombal, F. T., Watts, J. McK., Watkinson, G., and Goligher, J. C. (1965). Intraperitoneal perforation of the colon in ulcerative colitis. Proc. roy. Soc. Med., 58, 713-715.
Edwards, F. C., and Truelove, S. C. (1964). The course and prognosis of ulcerative colitis. Part III. Complications, Gut, 5, 1-15.

Ewart, W. B., and Lennard-Jones, J. E. (1960). Corticosteroids in preoperative medical management of ulcerative colitis. Do they affect surgical success? Lancet, 2, 60-64.

Goligher, J. C., Hoffman, D. C., and de Dombal, F. T. (1970). Surgical treatment of severe attacks of ulcerative colitis, with special reference to the advantage of early operation. Brit. med. J., 4, 703-706.

Hughes, E. S. R. (1964). Surgery in ulcerative colitis. Med. J. Aust., 1, 743-748.

Jalan, K. N., Sircus, W., Card, W. I., Falconer, C. W. A., Bruce, J., Crean, G. P., McManus, J. P. A. Small, W. P., and Smith, A. N. (1969a). An experience of ulcerative colitis. I-Toxic dilation in 55 cases. Gastroenterology, 57, 68-82.

Jalan, K. N., Smith, A. N., Ruckley, C. V., Falconer, C. W. A., Small, W. P., and Prescott, R. J. (1969b). Perineal wound healing in ulcerative colitis. Brit. J. Surg., 56, 749-753.

Lennard-Jones, J. E., and Vivian, A. B. (1960). Fulminating ulcerative colitis. Recent experience in management. Brit. med. J., 2, 96102.

Todd, I. P. (1961). Carcinoma of the rectum following ileoproctostomy and colectomy for ulcerative colitis. Proc. roy. Soc. Med., 54, 514-516.

Watts, J. McK., de Dombal, F. T., and Goligher, J.C. (1966a). Early results of surgery for ulcerative colitis. Brit. J. Surg., 53, 1005-1014.

Watts, J. McK., de Dombal, F. T., and Goligher, J. C. (1966b). Longterm complications and prognosis following major surgery for ulcer ative colitis. Brit. J. Surg., 53, 1014-1023.

\section{Part II The health of ileostomists}

SUMmaRY To the ileostomist who asks, 'Am I as healthy as the rest of the population', the answer can be a qualified affirmative. There is probably an increased likelihood of his developing calculi in the urinary tract but, apart from this, there is no suggestion of diseases of a general nature to which he is more subject than another individual of comparable age. If the surgery has been undertaken for ulcerative colitis in the absence of malignant change and the patient has survived one postoperative year, then an assurance can be given that life expectancy is little less than that in the general population.

This paper is concerned with the health of patients after the establishment of an ileostomy for chronic inflammatory disease of the colon. The sample consisted of 453 patients from 37 hospitals in the North East Metropolitan Hospital Region operated upon in the years 1955-66. The surgical results and sequelae have been fully dealt with in part $I$.

The investigation was conducted on behalf of the Ileostomy Association of Great Britain and Ireland whose members wished for an answer to the question, 'Are we as healthy as the rest of the population'. This paper is an attempt to answer that question.

Three hundred and seventy-one patients left hospital with an ileostomy and were followed up until 31 December 1967, ie, for varying periods up to 13 years after operation. Follow up was complete in all but four of these patients of whom two had emigrated.

\section{General Health}

The main diseases and conditions occurring during the years of follow up are given in Table I where the figures in brackets indicate the number of cases with Crohn's disease.

Peptic ulcer, diagnosed in seven patients, was in the stomach in four cases, the duodenum in two, and at the pylorus in one. Fourteen patients gave a history of peptic ulcer preoperatively (stomach 2 , duodenum 9 , pylorus 1 , unknown 2 ), giving a total incidence in the series of $4.6 \%$ (21 cases in 453 patients).

Gallstones were found in eight patients before and 